\title{
SYSTEMIC LUPUS ERYTHEMATOSUS IN MALE: TWO CASE REPORTS
}

\author{
MD. ISMAIL HOSSAIN ${ }^{1}$, SHAH MD. SARWER JAHAN ${ }^{2}$, MD. ASHRAFUL HAQUE ${ }^{3}$, ABM. MOBASHER ALAM ${ }^{4}$, \\ MAINUDDIN AHMED ${ }^{5}$, MD. ZAKIR HOSSAIN ${ }^{6}$
}

\begin{abstract}
Systemic lupus erythematosus (SLE) is the most common multisystem connective tissue disease. Around $90 \%$ of affected individuals are women, with peak onset in the second and third decades. Tissues of all system are damaged by pathogenic auto-antibodies and immune complexes. We report here two cases of SLE in male patient, presented with typical features of SLE. Though the disease is rare in male, but such type of manifestations should be investigated properly to exclude SLE.
\end{abstract}

Key words: Systemic lupus erythematosus, male, auto-antibodies, immune complex.

\section{Introduction}

Systemic lupus erythematosus (SLE) is a chronic inflammatory disease of unknown etiology that can affect the skin, joints, kidneys, lungs, nervous system, serous membranes and/or other organs of the body. Immunologic abnormalities, especially the production of a number of auto antibodies, are another prominent feature of the disease. The clinical course of SLE is variable and may be characterized by periods of remissions and relapses ${ }^{1}$.SLE occurs worldwide but the prevalence varies from country to country, with the most prevalence of 1:250 in African American women. In other population the prevalence varies to $1: 10000^{2}$. Male SLE is rare, ninety percent of cases are in women, and usually of child bearing age; but children, men, and elderly can also be affected ${ }^{3}$. The skin and/or mucous membranes are involved at some point in over 80 percent of patients with systemic lupus erythematosus (SLE) ${ }^{4,5,6}$. There is tremendous variability and diversity in the type of involvement, ranging from the classic butterfly rash to fixed lesions that may be associated with scarring and atrophy (also referred to as discoid lupus erythematosus). In addition, cutaneous bullae, oral and nasopharyngeal ulcers, cicatrizing and non-cicatrizing alopecia, and skin changes resulting from vasculitis may occur in patients with SLE. Renal involvement becomes clinically apparent in approximately 50 percent of patients; however, most of the remaining patients have subclinical disease that can be demonstrated if renal biopsy were performed. Renal involvement usually develops in the first few years of illness, and should be detected early by periodic urinalyses, quantitation of proteinuria, and estimation of the glomerular filtration rate (usually by monitoring the plasma creatinine concentration). Several forms of glomerulonephritis can occur and renal biopsy is useful to define the type and extent of renal involvement. We describe two case of male patient with SLE.

\section{Case Report: One}

A 25 years male patient admitted to medicine ward with history of skin rash, bodyache, fatigue and occasional fever for three months. Rash was erythematous, flat, fixed over his malar prominence sparing the nasolabial fold. There were some erythematous raised patches with adherent keratotic scales \& follicular plugging followed by atrophic scaring involving chest, back, forearms \& legs. He also gave history of unusual reaction to light on exposed skin. He had no history of oral ulcer, arthritis or features of serosities. Initial laboratory evaluation yielded as follows: Hb-9.9 gm/dl, ESR-60 mm in first hour, TC of WBC- $6000 /$ cumm, Platelet count$154,000 /$ cumm, DC of WBC revealed neutrophil- $65 \%$, lymphocyte- 30\%, monocyte- 01\%, eisonophil- 04\%, PCV-33.7\%. Urine R/M/E Shows- mild albuminuria, absent of cast, heat coagulation test was negative, urinary total protein was found $0.4 \mathrm{gm} /$ day. PBF was

1. Registrar, Department of Medicine, Rangpur Medical College Hospital.

2. Assistant Professor, Department of Medicine, Rangpur Medical College.

3. Assistant Professor, Department of Medicine, Rangpur Medical College.

4. Assistant Professor, Department of Nephrology, Rangpur Medical College.

5. Indoor Medical Officer, Department of Medicine, Rangpur Medical College \& Hospital, Rangpur.

6. Professor and Head, Department of Medicine, Rangpur Medical College.

Bangladesh J Medicine 2013; 24 : 82-85 
suggestive of combined deficiency anemia. CRP was $12 \mathrm{mg} / \mathrm{dl}$. ANA- 53.0 IU/ml, Anti-dsDNA- 400IU/ml. $\mathrm{X}$-ray chest $\mathrm{P} / \mathrm{A}$ view, ultrasonographic study of whole abdomen \& ECG showed no abnormalities. The paitent was treated by oral Hydoxychloroquine and Tachrolimus ointment application locally.

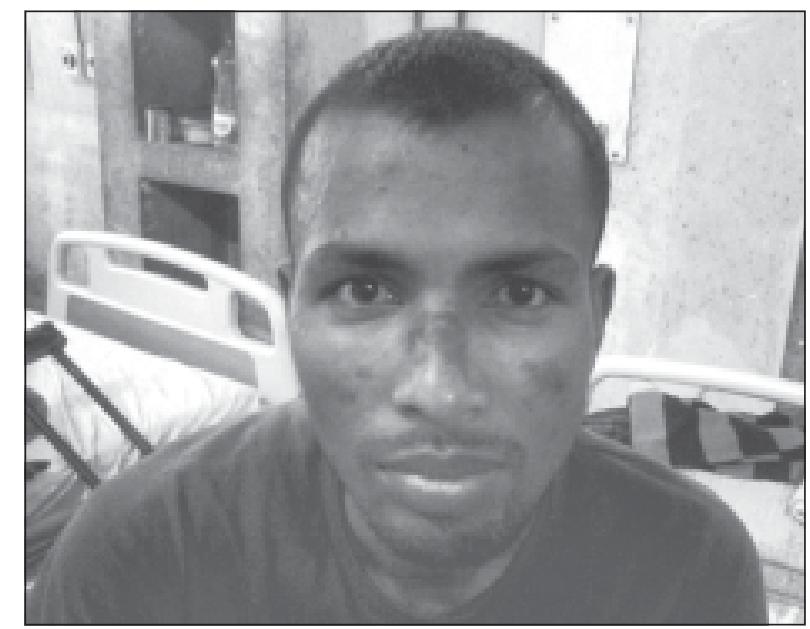

Fig.-1(A)

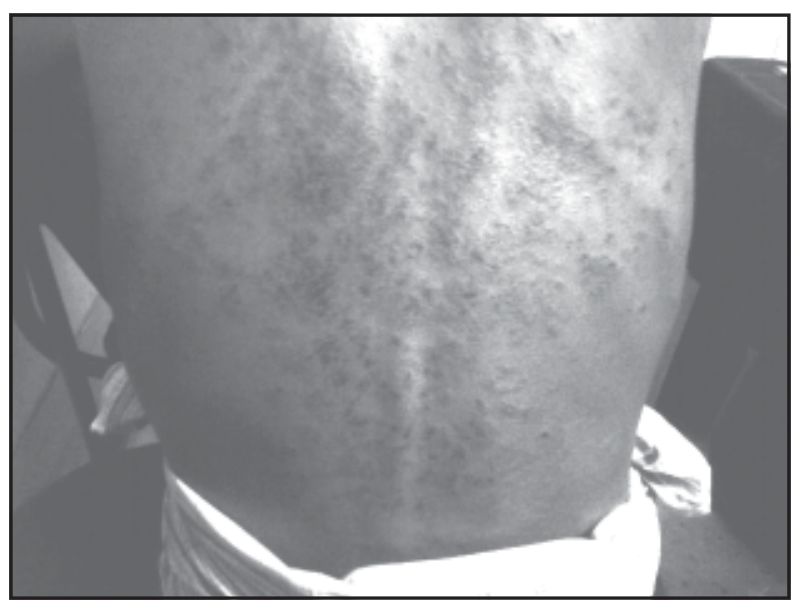

Fig.-1(A)

\section{Case Report: Two}

A 15 years male patient, normotensive, nondiabetic admitted to medicine department with a two weeks history of swelling of whole body. He also gave history of breathlessness which was more marked in lying posture. He had no history of fever, mayalgia, arthritis, oral ulcers, photosensitivity or rash in the skin and no significant past or family history. Physical examination revealed pitting ankle edema, ascites with features of right sided pleural effusion. Laboratory examination showed: Hb-10.0gm/dl, ESR$94 \mathrm{~mm}$ in first hour, total count of WBC- 3500/cumm, platelet count- $120,000 /$ cumm, the differential count of WBC showed neutrophil- 62\%, lymphocyte- 30\%, monocyte- 07\%, eisonophil- 01\%, PCV-35.6\%. Urine
$\mathrm{R} / \mathrm{M} / \mathrm{E}$ showed-moderate albuminuria, moderate granular cast $\&$ haematuria, heat coagulation test positive, urinary total protein- $6.6 \mathrm{gm} /$ day, CRP- 12 $\mathrm{mg} / \mathrm{dl}$, serum albumin- $1.52 \mathrm{gm} / \mathrm{dl}$, S.Cholesterol$285 \mathrm{mg} / \mathrm{dl}$, ultrasonography of whole abdomen showed huge ascites, X-ray chest P/A view revealed right sided pleural effusion. S.creatinine- $0.8 \mathrm{mg} / \mathrm{dl}$. Hepatitis B surface antigen (HBs Ag), hepatitis $\mathrm{C}$ virus (Anti $\mathrm{HCV}$ ) and R.A test was negative, C3 was $0.17 \mathrm{gm} / 1(0.9-$ $1.8 \mathrm{gm} / 1)$, ANA was positive (120 IU/ml), Anti ds DNA was also positive $(250 \mathrm{IU} / \mathrm{ml})$. Then renal biopsy was done which shows features compatible with diffuse proliferative lupus nephritis, ISN/RPS WHO class IV. The patient was diagnosed as a case of lupus nephritis and the patient was treated by pulse therapy with Methylprednisolone and Cyclophosphamide. Advised for regular followup.

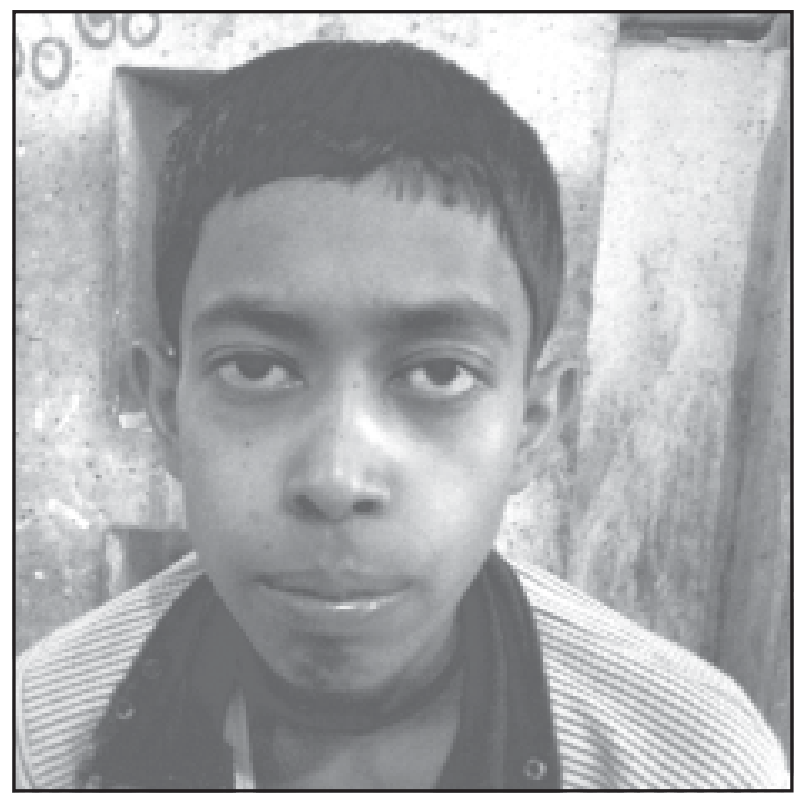

Fig.-2(A)

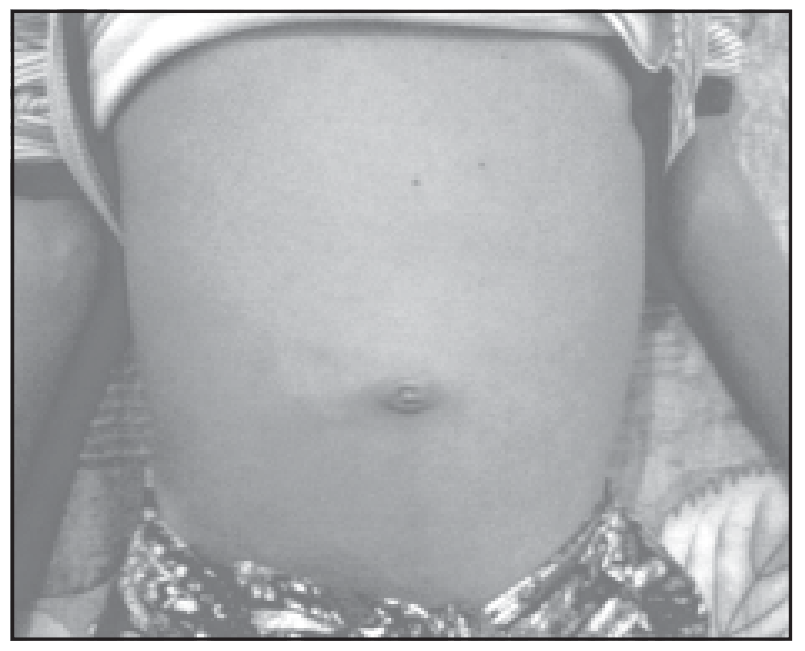

Fig.-2(A) 


\section{Discussion}

SLE is a multisystem autoimmune disease with a broad spectrum of clinical presentations ${ }^{7}$. The prevalence of SLE is much lower in males than females and male SLE patients may have a less favorable outcome ${ }^{8}$.

In our series there were two patients, one was middle age man $\&$ another was a young boy. In case one, patient had typical clinical features. Studies showed fatigue, fever, and bodyache were typically present some time during the course of the disease, occurring in 50 to 100 percent of patients. In SLE fatigue is the most common complain and occasionally the most debilitating. It occurs in 80 to 100 percent of patients and its presence in not clearly correlated with other measures of disease activity ${ }^{9-12}$. Fatigue was strongly associated with diminished exercise tolerance ${ }^{13,14}$. The patient complains of acute butterfly rash, characterized by erythema in a malar distribution over the cheeks and bridge of the nose [picture 1(A)]. Various studies showed it appears in approximately one-half of patients, usually after ultraviolet (UV) light exposure and is frequently mistaken for sunburn. The rash may precede other symptoms of lupus by months or even years or might be accompanied by other symptoms and sign of acute SLE. He had also some discoid rash over chest, back $\&$ leg [picture $1(\mathrm{~B})$ ]. These types of discoid lesions develop in up to 25 percent of patients with SLE but might also occur in the absence of any other clinical feature of SLE (14). Patients with only discoid lupus erythematosus (DLE) generally had a negative or low-titer antinuclear antibody (ANA), and rarely had anti-Ro antibodies (15). In our first case having DLE had low titer ANA that was consistent with other study. He had also photosensitivity on exposure to sun. Photosensitivity on exposure to UV-B radiation found in sunlight or fluorescent lights, ${ }^{(16)}$ occurs in 60 to 100 percent of patients with $\mathrm{SLE}^{17,18}$. Some patients is also sensitive to UV-A (as from a photocopier ${ }^{19}$ ), and might even be sensitive to the visible light spectrum.

In second case, the young boy presented with anasarca without other classical feature of SLE. Urine analysis shows massive proteinuria (UTP- 6.6gm/day). Then renal biopsy showed features were compatible with diffuse proliferative lupus nephritis, ISN/RPS WHO class IV. Renal involvement is common in systemic lupus erythematosus (SLE). An abnormal urinalysis with or without an elevated plasma creatinine concentration is present in a large proportion of patients at the time of diagnosis of lupus nephritis. The most frequently observed abnormality in patients with lupus nephritis is proteinuria (20). There are a number of types of renal disease in SLE, usually differentiated with a renal biopsy, with immune complex-mediated glomerular diseases being most common. In addition, nonlupus renal diseases may be seen (21).Most patients with lupus nephritis have an immune complex-mediated glomerular disease. So, the second case was diagnosed as diffuse lupus nephritis. With diffuse lupus nephritis or class IV disease, more than 50 percent of glomeruli display endocapillary with or without extracapillary glomerulonephritis in a segmental (involving less than 50 percent of the glomerular tuft) or global pattern; mesangial abnormalities also may be observed (22). Diffuse lupus is associated with subendothelial deposits, at least during the active phase. The presence of diffuse wire loop deposits, but with little or no glomerular proliferation, is also considered class IV disease.

In conclusion we could say when a male patient with fever, skin manifestation or anasarca with proteinuria, besides the other etiologies, autoimmune diseases like SLE should be kept in mind.

\section{References}

1. Walling HW, Sontheimer RD. Cutaneous lupus erythematosus: issues in diagnosis and treatment. Am J Clin Dermatol 2009; 10:365.

2. Pistiner $M$, Wallace DJ, Nessim S, et al. Lupus erythematosus in the 1980s: a survey of 570 patients. Semin Arthritis Rheum 1991; 21:55.

3. Petri M. Dermatologic lupus: Hopkins Lupus Cohort. Semin Cutan Med Surg 1998; 17:219.

4. Callen JP. Cutaneous lupus erythematosus: a personal approach to management. Australas $\mathrm{J}$ Dermatol 2006; 47:13.

5. Lin JH, Dutz JP, Sontheimer RD, Werth VP. Pathophysiology of cutaneous lupus erythematosus. Clin Rev Allergy Immunol 2007; 33:85.

6. Durosaro O, Davis MD, Reed KB, Rohlinger AL. Incidence of cutaneous lupus erythematosus, 19652005: a population-based study. Arch Dermatol 2009; 145:249.

7. Perez-Mercado AE, Vila-Perez S. Cytomegalovirus as a trigger for systemic lupus erythematosus. J Clin Rheumatol. 2010;16(7):335-337.

8. Lu LJ, Wallace DJ, Ishimori ML, Scofield RH, Weisman MH. Review: Male systemic lupus erythematosus: a review of sex disparities in this disease. Lupus. 2010;19(2):119-129.

9. McKinley PS, Ouellette SC, Winkel GH. The contributions of disease activity, sleep patterns, and depression to fatigue in systemic lupus erythematosus. A proposed model. Arthritis Rheum $1995 ; 38: 826$. 
10. Schwartz JE, Jandorf L, Krupp LB. The measurement of fatigue: a new instrument. J Psychosom Res 1993; 37:753.

11. Tench CM, McCurdie I, White PD, D'Cruz DP. The prevalence and associations of fatigue in systemic lupus erythematosus. Rheumatology (Oxford) 2000; 39:1249.

12. Jump RL, Robinson ME, Armstrong AE, et al. Fatigue in systemic lupus erythematosus: contributions of disease activity, pain, depression, and perceived social support. J Rheumatol 2005; 32:1699.

13. Robb-Nicholson LC, Daltroy L, Eaton H, et al. Effects of aerobic conditioning in lupus fatigue: a pilot study. Br J Rheumatol 1989; 28:500.

14. Keyser RE, Rus V, Cade WT, et al. Evidence for aerobic insufficiency in women with systemic Lupus erythematosus. Arthritis Rheum 2003; 49:16.

15. Provost TT. The relationship between discoid and systemic lupus erythematosus. Arch Dermatol 1994; 130:1308

16. Rihner M, McGrath H Jr. Fluorescent light photosensitivity in patients with systemic lupus erythematosus. Arthritis Rheum 1992; 35:949.
17. Wysenbeek AJ, Block DA, Fries JF. Prevalence and expression of photosensitivity in systemic lupus erythematosus. Ann Rheum Dis 1989; 48:461.

18. Callen JP, Kulick KB, Stelzer G, Fowler JF. Subacute cutaneous lupus erythematosus. Clinical, serologic, and immunogenetic studies of forty-nine patients seen in a nonreferral setting. J Am Acad Dermatol 1986; 15:1227.

19. Klein LR, Elmets CA, Callen JP. Photoexacerbation of cutaneous lupus erythematosus due to ultraviolet A emissions from a photocopier. Arthritis Rheum 1995; 38:1152.

20. Clinical features of SLE. In: Textbook of Rheumatology, Kelley, WN, et al (Eds), WB Saunders, Philadelphia 2000.

21. Baranowska-Daca E, Choi YJ, Barrios R, et al. Nonlupus nephritides in patients with systemic lupus erythematosus: a comprehensive clinicopathologic study and review of the literature. Hum Pathol 2001; 32:1125.

22. Weening JJ, D’Agati VD, Schwartz MM, et al. The classification of glomerulonephritis in systemic lupus erythematosus revisited. J Am Soc Nephrol 2004; 15:241. 